\title{
Aggregation in Three Benzamide or Pyridylcarboxamide Hydrates: Formation of 1D Chains Comprising Water Molecules in a Chloro(pyridyl)benzamide Dihydrate
}

\author{
Pavle Mocilac, ${ }^{1}$ John F. Gallagher, ${ }^{1, *}$ Christian Jelsch ${ }^{2}$
}

\author{
1 School of Chemical Sciences, Dublin City University, Dublin 9, Ireland \\ 2 CRM², CNRS UMR 7036, Faculté des Sciences et Technologies, Université de Lorraine, BP 70239, Boulevard des Aiguillettes, 54506 Vandoeuvre-lès-Nancy, France \\ * Corresponding author's e-mail address: john.gallagher@dcu.ie
}

RECEIVED: April 14, 2018 * REVISED: June 26, 2018 * ACCEPTED: June 26, 2018

THIS PAPER IS DEDICATED TO DR. BISERKA KOJIĆ-PRODIĆ ON THE OCCASION OF HER 80 ${ }^{\mathrm{TH}}$ BIRTHDAY

\begin{abstract}
Three benzamide hydrated derivatives as para-methyl- $\mathrm{N}$-(3-pyridyl)benzamide monohydrate (I) or $\mathrm{Mpm} \cdot \mathrm{H}_{2} \mathrm{O} ; \mathrm{N}$-(3-fluorophenyl)-4pyridylcarboxamide monohydrate (II) or $\mathrm{NpmF} \cdot \mathrm{H}_{2} \mathrm{O}$ and para-chloro- $\mathrm{N}$-(3-pyridyl)benzamide dihydrate (III) or $\mathrm{Clpm} \cdot 2 \mathrm{H}_{2} \mathrm{O}$ are obtained from a series of crystallization experiments using a range of solvents to obtain polymorphs and solvates (hydrates). Most of the crystallization experiment attempts did not provide hydrates and yielded the starting parent crystalline materials. However, from the experiments, two benzamides, $\mathrm{Mpm}$ as a monohydrate and $\mathrm{Clpm}$ as a dihydrate were isolated and together with a carboxamide monohydrate as $\mathrm{NpmF} \cdot \mathrm{H}_{2} \mathrm{O}$ are reported herein. The water molecules play a key role in crystal structure formation using classical hydrogen bonding via amide $\mathrm{N}-\mathrm{H} \cdots \mathrm{OH}_{2}, \mathrm{O}-$ $\mathrm{H} \cdots \mathrm{N}_{\text {pyridine }}$ and $\mathrm{O}-\mathrm{H} \cdots \mathrm{O}=\mathrm{C}$ interactions. They compensate for the excess of strong hydrogen bonding acceptors over donors in the benzamide/pyridinecarboxamide molecules, by participating as $\mathrm{O}-\mathrm{H}$ hydrogen bond donors twice and usually as an $\mathrm{O}$ acceptor once. In the Clpm dihydrate, both water molecules form hydrogen bonded chains along the $a$-axis direction. The lack of hydrate formation in the majority of related benzamides is presumably related to the relative hydrophobicity of these compounds.
\end{abstract}

Keywords: benzamide, carboxamide, contact enrichment, hydrate, hydrogen bonding, interactions, structural systematics

\section{INTRODUCTION}

$\mathbf{M}$ ANY pharmaceutical drugs are non-polar organic based molecules with limited solubility in polar solvents and water. ${ }^{[1-6]}$ This solubility problem can hamper bioavailability in aqueous solutions and requires considerable time and effort in the design of drug delivery systems that are effective in delivery and cost. Significant efforts have been devoted to overcoming this problem over the last few decades using a variety of strategies and has been commented on in several papers and comprehensive reviews. ${ }^{[1,2,6]}$

In this paper we describe three aromatic amide hydrates (I)-(III). These benzamide/carboxamide hydrates are obtained from crystallization reactions using a range of solvents and conditions with the purpose of generating polymorphs and solvates (hydrates) from extensive series of benzamides ${ }^{[7,8]}$ and pyridinecarboxamide derivatives. ${ }^{[9,10]}$ Most crystallization attempts did not provide solvates (or hydrates) and yielded the same parent products as those isolated and reported previously. ${ }^{[7-10]}$ However three benzamide and carboxamide hydrates were obtained and are reported herein as two benzamide hydrates $\mathrm{Mpm} \cdot \mathrm{H}_{2} \mathrm{O}$, (I) and $\mathrm{Clpm} \cdot \mathbf{2} \mathrm{H}_{2} \mathrm{O}$, (III) and a carboxamide monohydrate as $\mathrm{NpmF} \cdot \mathrm{H}_{2} \mathrm{O}$, (II), (Scheme 1).

\section{EXPERIMENTAL}

\section{Synthesis and Crystallisation}

The parent benzamide/carboxamides of compounds (I) and (II) are $\mathbf{M p m}$ and $\mathbf{N p m F}$ and have been reported previously as part of extensive structural systematics studies. ${ }^{[7,10]}$ Three derivatives of $\mathbf{M p m}^{[7]}$ and $\mathbf{N p m F}{ }^{[10]}$ (in addition to 
<smiles>Cc1ccc(C(=O)Nc2cccnc2)cc1</smiles><smiles>O=C(Nc1cccc(F)c1)c1ccncc1</smiles><smiles>CCOC(=O)c1ccc(Cl)cc1</smiles>

Scheme 1. Molecular structures of the (I)-(III) hydrates.

Clpm) yield hydrates, the former two as monohydrates and Clpm as a dihydrate, when recrystallised from solvents with water being incorporated adventitiously in the crystallization process or from aqueous mixtures. The Mpm hydrate was recrystallized from ethyl acetate, NpmF from diethyl ether and Clpm from acetonitrile/water solution to yield hydrates (I)-(III) as crystalline materials (Figures 1a-c).

\section{Refinement}

Crystal structure, data collection and structure refinement details are summarised in Table 1 . The refinements of the three crystal structures were performed using similar strategies, as described previously. ${ }^{[7]}$ Hydrogen atoms attached to $\mathrm{C}$ atoms were treated as riding using the SHELXL14 ${ }^{[11]}$ defaults at 294(1) K with $\mathrm{C}-\mathrm{H}=0.93 \AA$ and $U_{\text {iso }}(\mathrm{H})=1.2 U_{\text {eq }}(\mathrm{C})$ (for aromatic) and the methyl $\mathrm{C}-\mathrm{H}=0.96$ $\AA$ (aliphatic) and $U_{\text {iso }}(\mathrm{H})=1.5 U_{\text {eq }}(\mathrm{C})$. All amino $\mathrm{N}-\mathrm{H}$ and water $\mathrm{H}$ atoms were refined on $x, y, z$ and with isotropic displacement parameters. The $\mathrm{Clpm} \cdot \mathbf{2} \mathbf{H}_{2} \mathbf{O}$ dataset was collected using $\mathrm{Cu}$ radiation and as a hemisphere of data to $100 \%$ completion to $120^{\circ}$.

All experiments were performed using a Xcalibur, Sapphire3, Gemini Ultra diffractometer with experiments undertaken at 294(1) K. ${ }^{[12]}$ Analytical absorption corrections were performed on colourless crystals using ABSFAC.[13] Computer and graphics programs used include: CrysAlisPRO, ,12] SHELXS14/6, SHELXL14, ${ }^{[11]}$ PLATON ${ }^{[14]}$ and Mercury. ${ }^{[15]}$

\section{RESULTS AND DISCUSSION}

\section{Structural Commentary}

From the crystallization experiments two benzamide hydrates were obtained as $\mathbf{M p m} \cdot \mathbf{H}_{2} \mathbf{O}$, (I) and the dihydrate $\mathrm{Clpm} \cdot \mathbf{2} \mathrm{H}_{2} \mathrm{O}$, (III) as well as a pyridinecarboxamide monohydrate $\mathbf{N p m F} \cdot \mathbf{H}_{\mathbf{2}} \mathbf{O}$, (II) (Figures $1 \mathrm{a}-\mathrm{c}$ ). The experimental details are in Table 1 with selected interactions in Table 2.

The crystal structure of the unsolvated $\mathrm{Mpm}$ or para-methyl- $N$-(3-pyridyl)benzamide $\quad$ (FADZOB) ${ }^{[16]}$ has been reported by us previously ${ }^{[7]}$ and crystallises with $Z^{\prime}=4$ (molecules A-D) in the triclinic space group P1. For the $\mathrm{Mpm} \cdot \mathrm{H}_{2} \mathrm{O}$ structure as isolated from ethyl acetate, the aromatic $\mathrm{C}_{6}$ and $\mathrm{C}_{5} \mathrm{~N}$ rings are essentially coplanar at
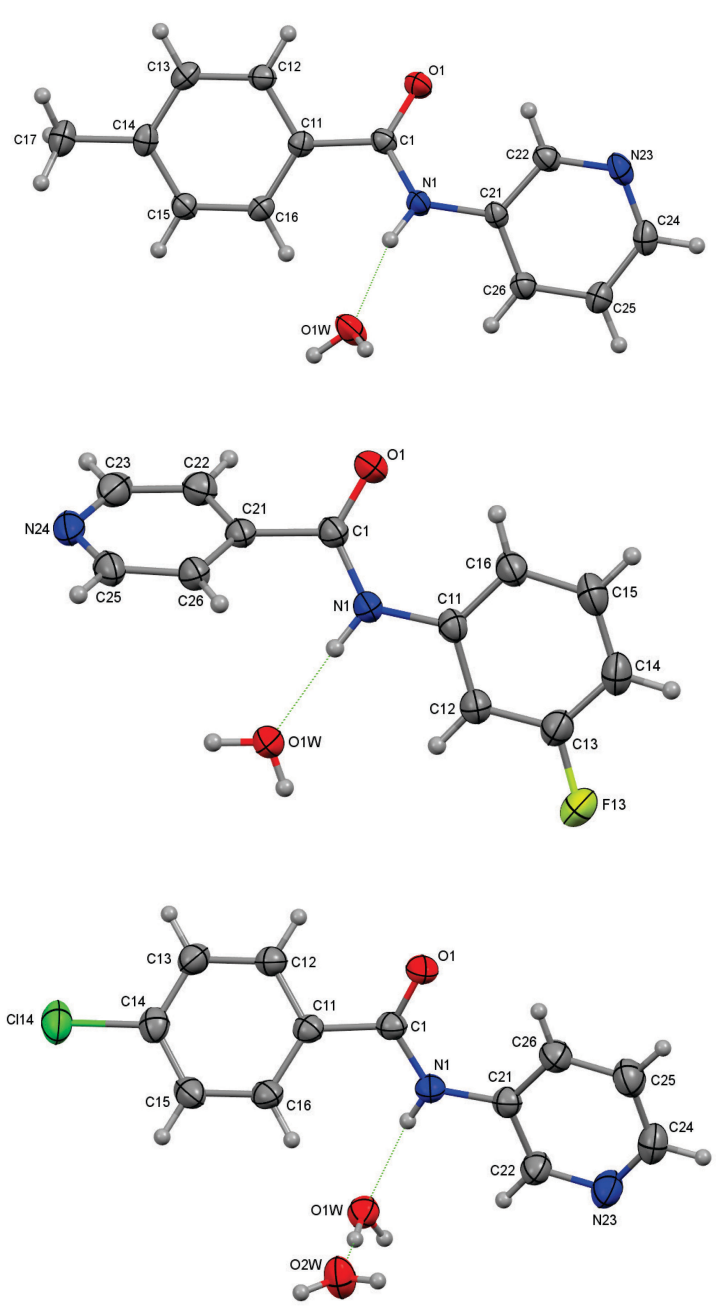

Figure 1. ORTEP views of the asymmetric units of the structures of (I) to (III) with the atomic numbering scheme. Displacement ellipsoids are drawn at the $30 \%$ probability level. Only the major conformation of $\mathrm{NpmF} \cdot \mathrm{H}_{2} \mathrm{O}$ is depicted.

$1.37(9)^{\circ}$, and at angles of $30.97(14)^{\circ}$ and $31.30(14)^{\circ}$ to the five atom (C)OCN(C) group incorporating the amide bridge. These geometric data are similar to the conformations of molecules $\mathrm{C}, \mathrm{D}$ in $\mathbf{M p m}^{[7]}$ as noted with interplanar angles of $1.5(2)^{\circ}, 1.9(2)^{\circ}$ (for $C_{6} / C_{5} N$ ); 24.47(16) ${ }^{\circ}, 24.79(16)^{\circ}$ (for 
Table 1. Crystallographic Experimental details for (I), (II) and (III).

\begin{tabular}{|c|c|c|c|}
\hline Crystal structures & $\mathrm{Mpm} \cdot \mathrm{H}_{2} \mathrm{O}$ & $\mathrm{NpmF} \cdot \mathrm{H}_{2} \mathrm{O}$ & $\mathrm{Clpm} \cdot 2 \mathrm{H}_{2} \mathrm{O}$ \\
\hline \multicolumn{4}{|l|}{ Crystal data } \\
\hline Chemical formula & $\mathrm{C}_{13} \mathrm{H}_{12} \mathrm{~N}_{2} \mathrm{O} \cdot \mathrm{H}_{2} \mathrm{O}$ & $\mathrm{C}_{12} \mathrm{H}_{9} \mathrm{FN}_{2} \mathrm{O} \cdot \mathrm{H}_{2} \mathrm{O}$ & $\mathrm{C}_{12} \mathrm{H}_{9} \mathrm{ClN}_{2} \mathrm{O} \cdot 2\left(\mathrm{H}_{2} \mathrm{O}\right)$ \\
\hline$M_{r}$ & 230.26 & 234.23 & 268.69 \\
\hline Crystal system, space group & Monoclinic, $C c$ & Monoclinic, $P 2_{1} / c$ & Monoclinic, $P 2_{1} / c$ \\
\hline$a, b, c(\AA)$ & $\begin{array}{c}\text { 15.2403(4), } \\
6.1683(1) \\
13.5400(4)\end{array}$ & $\begin{array}{c}\text { 8.5053(5), } \\
7.1083(4) \\
18.9462(13)\end{array}$ & $\begin{array}{c}\text { 4.5623(1), } \\
\text { 13.8473(3), } \\
20.5984(5)\end{array}$ \\
\hline$\beta\left(^{\circ}\right)$ & $111.516(3)$ & $93.768(5)$ & $95.218(2)$ \\
\hline$V\left(\AA^{3}\right)$ & $1184.15(6)$ & $1142.98(12)$ & $1295.92(5)$ \\
\hline$F(000), Z$ & 488,4 & 488,4 & 560,4 \\
\hline$\theta$ range $\left(^{\circ}\right)$ for cells & $3.4-27.4$ & $3.6-27.2$ & $3.2-62.4$ \\
\hline$\mu\left(\mathrm{mm}^{-1}\right)$ & 0.09 & 0.11 & 2.65 \\
\hline Crystal shape, colour & Block, colourless & Block, colourless & Plate, colourless \\
\hline Crystal size $(\mathrm{mm})$ & $0.38 \times 0.26 \times 0.17$ & $0.44 \times 0.41 \times 0.28$ & $0.53 \times 0.11 \times 0.05$ \\
\hline \multicolumn{4}{|l|}{ Data collection } \\
\hline Radiation type, source & Enhance (Mo K $\alpha)$ & Enhance (Mo Ka) & Enhance Ultra (CuK $\alpha)$ \\
\hline$T_{\min }, T_{\max }$ & $0.980,0.988$ & $0.920,0.949$ & $0.523,0.893$ \\
\hline $\begin{array}{l}\text { Measured, independent, observed }[/>2 \sigma(/)] \\
\text { reflection }\end{array}$ & 4098, 2170, 1937 & $7787,2483,2002$ & $7172,2056,1778$ \\
\hline$R_{\text {int }}$ & 0.016 & 0.011 & 0.023 \\
\hline$(\sin \theta / \lambda)_{\max }\left(\AA^{-1}\right)$ & 0.648 & 0.645 & 0.576 \\
\hline \multicolumn{4}{|l|}{ Refinement } \\
\hline$R\left[F^{2}>2 \sigma\left(F^{2}\right)\right], w R\left(F^{2}\right), S$ & $0.030,0.078,1.04$ & $0.036,0.102,1.06$ & $0.039,0.116,1.04$ \\
\hline Reflections, Parameters, Restraints & $2170,167,2$ & $2483,171,0$ & $2056,183,0$ \\
\hline$\Delta \rho_{\max }, \Delta \rho_{\min }\left(e . \AA^{-3}\right)$ & $0.09,-0.16$ & $0.16,-0.14$ & $0.23,-0.24$ \\
\hline $\begin{array}{l}\text { Absolute structure, } \\
\text { Parameter }\end{array}$ & $\begin{array}{l}\text { Flack } \times \text { using } 710 \text { quotients } \\
{[(I+)-(I-)] /[(I+)+(I-)] . \text { Parameter }=1.5(6)}\end{array}$ & - & - \\
\hline
\end{tabular}

$\mathrm{C}_{6} /$ amide)and $24.16(16)^{\circ}, 24.79(16)^{\circ}$ (for $\mathrm{C}_{5} \mathrm{~N} /$ amide), respectively. The introduction of the water into the crystal structure of (I) is accommodated by rotation of the central amide group by $6-7^{\circ}$ closer to co-planarity with the aromatic rings as compared with the $\mathbf{M p m}$ parent structure. ${ }^{[7]}$

The Mpm hydrate shows the clear role that the water molecule plays in the molecular assembly of (I) and overall crystal structure stability (Figure 2). Water molecules link the Mpm benzamides into 1D chains using a $C(7)$ graph set via $\mathrm{N}-\mathrm{H}_{\text {.... }} \mathrm{OH}_{2}$ and $\mathrm{O}-\mathrm{H} \cdots \mathrm{N}_{\text {pyridine }}$ hydrogen bonds

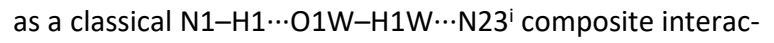
tion (Table 2). This hydrogen bonded assembly is arranged parallel with the (11) $)$ plane. The $\mathrm{H}_{2} \mathrm{O}$ molecule in the Mpm hydrate crystal structure is a hydrogen bond donor twice ( $\mathrm{H} 1 \mathrm{~W}, \mathrm{H} 2 \mathrm{~W}$ to the pyridine $\mathrm{N} 23^{\mathrm{i}}$ and amide $\mathrm{O}^{\mathrm{ii}}$; Table 2) and acceptor only once (O1W, from the amide N1-H1), which compensates for the presence of one strong donor $\mathrm{N} 1-\mathrm{H} 1$ versus two strong acceptors on the $\mathrm{Mpm}$ benzamide molecule (as 01, N23). This gives a crystal structure with a balanced total of three strong hydrogen bonding donor and three acceptor groups with $D: A=(3,3)$. A similar hydrogen bonding pattern involving the water molecule occurs in the NpmF hydrate crystal structure of (II) (see below). In the structure of (I), the O1W water molecules use their second $\mathrm{O}-\mathrm{H}$ moiety to link benzamides via longer $\mathrm{O}-\mathrm{H} \cdots \mathrm{O}=\mathrm{C}$ interactions into cross linked $\mathrm{C}(6)$ chains while extending the interactions into a 3D structure. The two weak $\mathrm{C}-\mathrm{H} \cdots \mathrm{O}=\mathrm{C}$ contacts per molecule have little overall effect on the crystal structure.

In comparison with the crystal structure of $\mathrm{Mpm}$. $\mathbf{H}_{\mathbf{2}} \mathrm{O}(\mathrm{I})$, there are small differences between the two sets of similar though independent molecules (A, B and C, D) in the unsolvated $\mathbf{M p m} .^{\left[{ }^{7]}\right.}$ Given the unusual crystal structure and unexpected number of molecules in the asymmetric unit ( $Z^{\prime}$ $=4)^{[17]}$ it can be surmised that the parent $\mathrm{Mpm}$ structure could be the initial kinetic crystallisation product isolated from ethyl acetate. 
Table 2. Selected hydrogen-bond parameters in (I) to (III).

\begin{tabular}{|c|c|c|c|c|}
\hline$D-H \cdots A$ & $D-H / \AA$ & $H \cdots A / \AA$ & $D \cdots A / \AA$ & $D-\mathrm{H} \cdots A /^{\circ}$ \\
\hline \multicolumn{5}{|c|}{$\mathrm{Mpm} \cdot \mathrm{H}_{2} \mathrm{O}$} \\
\hline $\mathrm{N} 1-\mathrm{H} 1 \cdots \mathrm{O} 1 \mathrm{~W}$ & $0.90(3)$ & $1.98(3)$ & $2.863(2)$ & $166(2)$ \\
\hline $\mathrm{O} 1 \mathrm{~W}-\mathrm{H} 1 \mathrm{~W} \cdots \mathrm{N} 23^{\mathrm{i}}$ & $0.88(4)$ & $1.97(4)$ & $2.847(2)$ & $172(3)$ \\
\hline $\mathrm{O} 1 \mathrm{~W}-\mathrm{H} 2 \mathrm{~W} \cdots \mathrm{O} 1^{\mathrm{ii}}$ & $0.81(4)$ & $2.15(4)$ & $2.965(3)$ & $174(3)$ \\
\hline $\mathrm{C} 22-\mathrm{H} 22 \cdots \mathrm{O} 1$ & 0.93 & 2.38 & $2.874(3)$ & 113 \\
\hline \multicolumn{5}{|c|}{$\mathrm{NpmF} \cdot \mathrm{H}_{2} \mathrm{O}$} \\
\hline $\mathrm{N} 1-\mathrm{H} 1 \cdots \mathrm{O} 1 \mathrm{~W}$ & $0.870(15)$ & $1.927(16)$ & $2.7947(15)$ & $174.7(13)$ \\
\hline 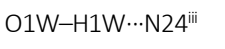 & $0.90(3)$ & $1.93(3)$ & $2.8273(16)$ & $178(2)$ \\
\hline $\mathrm{O} 1 \mathrm{~W}-\mathrm{H} 2 \mathrm{~W} \cdots \mathrm{O} 1^{\mathrm{iv}}$ & $0.81(2)$ & $2.02(2)$ & $2.8247(15)$ & $173(2)$ \\
\hline $\mathrm{C} 16-\mathrm{H} 16 \cdots \mathrm{O} 1$ & 0.93 & 2.32 & $2.8846(17)$ & 119 \\
\hline $\mathrm{C} 22-\mathrm{H} 22 \cdots \mathrm{O} 1^{v}$ & 0.93 & 2.46 & $3.3824(16)$ & 175 \\
\hline \multicolumn{5}{|c|}{$\mathrm{Clpm} \cdot 2 \mathrm{H}_{2} \mathrm{O}$} \\
\hline $\mathrm{N} 1-\mathrm{H} 1 \cdots \mathrm{O} 1 \mathrm{~W}$ & $0.83(2)$ & $2.16(2)$ & $2.992(2)$ & $172.6(19)$ \\
\hline $\mathrm{O} 1 \mathrm{~W}-\mathrm{H} 1 \mathrm{~W} \cdots \mathrm{O} 2 \mathrm{~W}$ & $0.89(2)$ & $1.80(2)$ & $2.684(2)$ & $169(2)$ \\
\hline $\mathrm{O} 1 \mathrm{~W}-\mathrm{H} 2 \mathrm{~W} \cdots \mathrm{N} 23^{\mathrm{vi}}$ & $0.83(3)$ & $1.98(3)$ & $2.802(2)$ & $168(3)$ \\
\hline $\mathrm{O} 2 \mathrm{~W}-\mathrm{H} 3 \mathrm{~W} \cdots \mathrm{O} 1 \mathrm{~W}^{\mathrm{vii}}$ & ii $0.82(3)$ & $1.96(3)$ & $2.779(2)$ & $171(3)$ \\
\hline $\mathrm{O} 2 \mathrm{~W}-\mathrm{H} 4 \mathrm{~W} \cdots \mathrm{O} 1^{\mathrm{viii}}$ & $0.91(3)$ & $1.92(3)$ & $2.819(2)$ & $172(3)$ \\
\hline $\mathrm{C} 26-\mathrm{H} 26 \cdots \mathrm{O} 1$ & 0.93 & 2.27 & $2.841(2)$ & 119 \\
\hline
\end{tabular}

Symmetry code(s): (i) $x-1 / 2, y-1 / 2, z$; (ii) $x,-y+1, z+1 / 2$; (iii) $-x+1,-y+1,-z$; (iv) $x, y+1, z$; (v) $-x,-y,-z$; (vi) $-x+2,-y+1,-z+1$; (vii) $x+1, y, z$; (viii) $-x+2, y+1 / 2,-z+1 / 2$.

Fluorine positional disorder in the fluorinated aromatic ring is present in the $\mathrm{NpmF}$ molecule or $\mathrm{N}$-(3-fluorophenyl)-4-pyridylcarboxamide (AMUDIW) ${ }^{[10,16]}$ and is easily accommodated in the crystal structure. This is not unexpected due to free rotation about the $\mathrm{CN}-\mathrm{CC}$ torsion angle and interchange of the meta-F13 with $\mathrm{H} 15$ atoms to give a F13/F15 site occupation of $0.924(3): 0.076(3)$. This disorder was noted previously in the isomorphous NpoF (AMUDOC) and NomF (AMUFIY) structures ${ }^{[10,16]}$ (both in space group Cc), but not in the parent NpmF structure. Fluorine atom site disorder in fluorinated benzamides is quite common where ortho- or meta-fluorine atoms adopt either of two sites with the distinct conformations related by rotation of the aromatic ring by $180^{\circ} .{ }^{[18,19]}$ The structure of (II) can be considered to assemble from $\mathrm{N}-\mathrm{H} \cdots \mathrm{OH}_{2}$ and $\mathrm{O}-\mathrm{H} \cdots \mathrm{N}$ interactions about inversion centres as $\mathrm{R}_{4}^{4}(18)$ rings comprising two NpmF benzamide ${ }^{[10]}$ and two water molecules (Table 2; Figure 3). Within the grouping of $2 \times\left(\mathrm{NpmF} \cdot \mathrm{H}_{2} \mathrm{O}\right)$, tight parallel offset aromatic $\pi \cdots \pi$ stacking occurs with a short $\mathrm{N} 24 \cdots \mathrm{C} 25^{i}$ contact distance of 3.2036(18) $\AA$ and $\mathrm{C} 25 \cdots \mathrm{C} 25^{i}$ $=3.346(2) \AA ̊$ (symmetry code $i$ : Table 2 ). The remaining water $\mathrm{O}-\mathrm{H}$ donor per asymmetric unit forms an $\mathrm{O}-\mathrm{H} \cdots \mathrm{O}=\mathrm{C}$ interaction with the carbonyl $\mathrm{O}=\mathrm{C}$ group to link dimers into a 1D tape (ca. $20.5 \AA$ wide) parallel with the (104) plane;

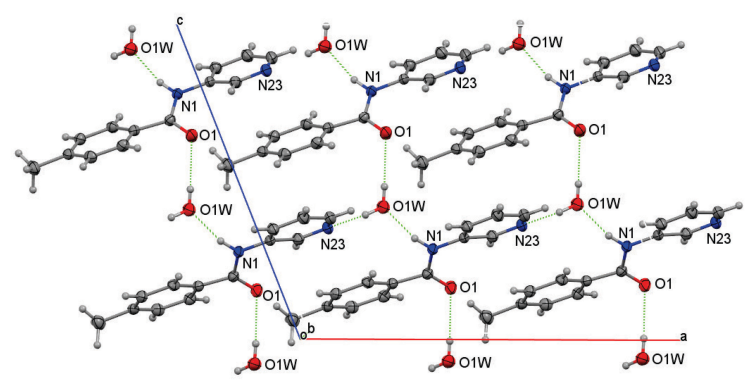

Figure 2. An ORTEP view of the crystal structure packing in (I) along the $b$-axis direction.

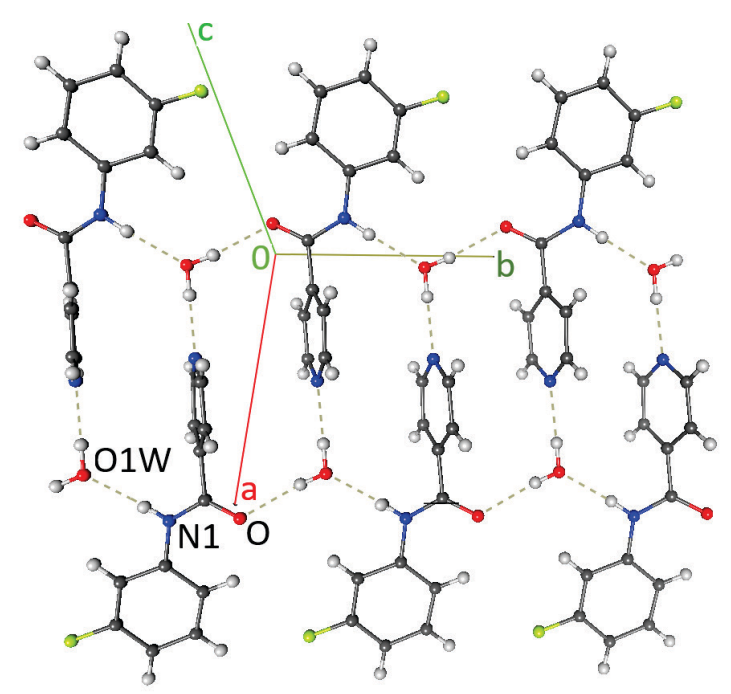

Figure 3. Autostereogram of the classical hydrogen bonding in the NpmF hydrate (II) with atoms depicted as spheres of size 0.15 times the van der Waals radius.

this is further linked by the formation of weaker $\mathrm{C}-\mathrm{H} \cdots \mathrm{O}$ interactions into columns. The inclusion of the water molecule in (II) bears a resemblance to the isomorphous pair of $\mathrm{CmoM} \cdot \mathrm{H}_{2} \mathrm{O}$ (VUXLIH) and $\mathrm{CmoBr} \cdot \mathrm{H}_{2} \mathrm{O}$ (VUXLIL) carbamate structures ${ }^{[20]}$ where two $\mathbf{C m o X}$ molecules $(\mathbf{X}=$ methyl $(\mathrm{M})$, $\mathrm{Br}$ ) are effectively linked by two bridging water molecules into cyclic hydrogen bonded $(\mathrm{N}-\mathrm{H} \cdots \mathrm{O}-\mathrm{H} \cdots \mathrm{N})_{2}$ rings of graph set size $R_{4}^{4}(14)$. The difference in hydrogen bonding cyclic ring sizes between (II) and $\mathrm{CmoX}^{[20]}$ is due to the para$\mathrm{N}_{\text {pyridine }}$ and nature of the amide bridge in (II).

In the $\mathrm{Clpm} \cdot \mathbf{2} \mathrm{H}_{2} \mathrm{O}$ or para-chloro- $\mathrm{N}$-(3-pyridyl)benzamide dihydrate structure, (III) as crystallized from acetonitrile/water solutions, molecules aggregate into cyclic dimers comprising two Clpm benzamide and two water molecules (with $\mathrm{O} 1 \mathrm{~W}$ ) about inversion centres forming a hydrogen bonded $\mathrm{R}_{4}^{4}(14)$ ring via $\mathrm{N}-\mathrm{H} \cdots \mathrm{O}-\mathrm{H} \cdots \mathrm{N}$ interactions (Figure 4a). This arrangement is similar in geometry to that observed in the isomorphous $\mathrm{CmoX}$ monohydrate pair (as noted), ${ }^{[20]}$ though with differences in the $\mathrm{O} \cdots \mathrm{N}$ hydrogen 
(a)

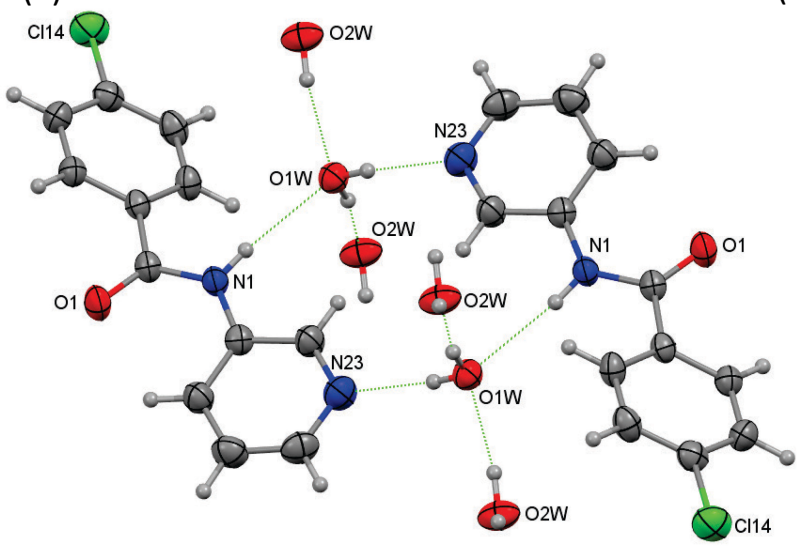

(b)

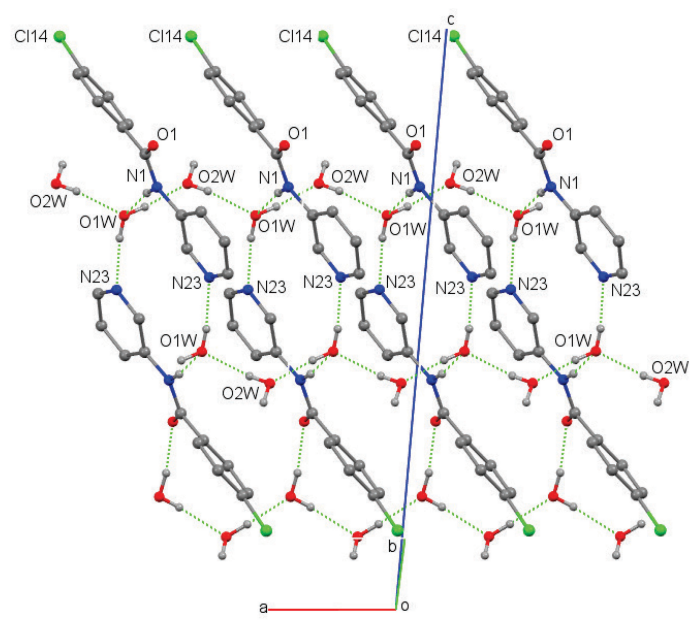

Figure 4. (a) An ORTEP view of the benzamides linked into dimers by water molecules in (III) and (b) An extended view of (III) with the unit cell and with aromatic hydrogens removed for clarity.

bonding distances of $\sim 0.15 \AA$ (Table 2). In Clpm $\cdot \mathbf{2} \mathbf{H}_{2} \mathbf{O}$ the second hydrogen bond donor from $\mathrm{O} 1 \mathrm{~W}$ forms a hydrogen bond to the second water molecule O2W (while O1W also accepts one hydrogen bond from a symmetry related $\mathrm{O} 2 \mathrm{~W}$ ) generating an alternating 1D hydrogen bonded water arrangement. Therefore, hydrogen bonding is maximised in $\mathrm{O} 1 \mathrm{~W}$ with two donors and two acceptors. The remaining $\mathrm{O} 2 \mathrm{~W}-\mathrm{H} 4 \mathrm{~W}$ donor forms $\mathrm{O}-\mathrm{H} \cdots \mathrm{O}=\mathrm{C}$ interactions (with the carbonyl $\mathrm{O} 1$ atom) to total two donors and one acceptor in $\mathrm{O}-\mathrm{H} \cdots \mathrm{O}$ hydrogen bonding. The O1W, O2W water molecules assemble in an alternating fashion as

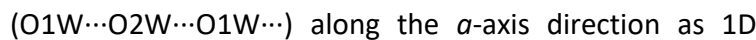
hydrogen bonded chains. This is not unusual and comparable 1D chains of water molecules have been reported which stabilise the crystal structure e.g. HUWQAS (Figure 5). ${ }^{[21]}$ In addition, two weak $\mathrm{C}-\mathrm{H} \cdots \mathrm{O}$ contacts augment the $\mathrm{O} 1 \mathrm{~W} . . . \mathrm{O} 2 \mathrm{~W}$ and $\mathrm{N} 1 \ldots \mathrm{O} 1 \mathrm{~W}$ interactions and the closest

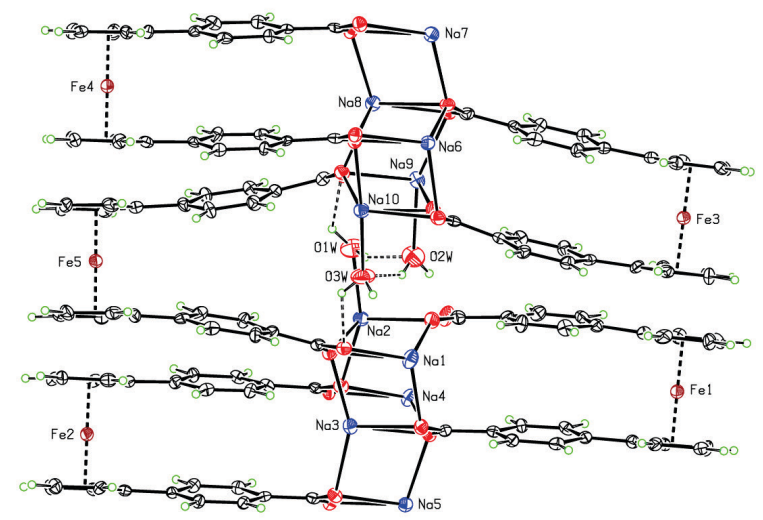

Figure 5. A view of the water molecules in the asymmetric unit of HUWQAS. [16,21]
C14-Cl14… Cl14ix halogen bonding contacts are 3.4353(9) $\AA$ and with $\mathrm{C} 14-\mathrm{Cl} 14 \cdots \mathrm{Cl} 14^{i x}=153.58(7)^{\circ}$ (symmetry code $i x$ $=-x, 1-y,-z)$.

An alternative way of understanding the hydrogen bonding process is to consider it to arise from a $1 \mathrm{D}$ relay of $(\mathrm{O}-\mathrm{H} \cdots \mathrm{O}-\mathrm{H} \cdots)$ interactions as $(\cdots \mathrm{O} 1 \mathrm{~W}-\mathrm{H} 1 \mathrm{~W} \cdots \mathrm{O} 2 \mathrm{~W}-$ $\mathrm{H} 3 \mathrm{~W} \cdots \mathrm{O} 1 \mathrm{~W}-\mathrm{H} 1 \mathrm{~W} \cdots)_{n}$ with both water molecules using their two remaining $\mathrm{O}-\mathrm{H}$ donors to form $\mathrm{O}-\mathrm{H} \cdots \mathrm{N}_{\text {pyr }}$ and $\mathrm{O}-$ $\mathrm{H} \cdots \mathrm{O}=\mathrm{C}$ interactions. The remaining classical interaction involves the amide $\mathrm{N} 1-\mathrm{H} 1 \cdots \mathrm{O} 1 \mathrm{~W}$ hydrogen bond.

\section{Structural Summary}

The three hydrate structures (I) to (III) show features that enhance their supramolecular stability. Hydrogen bonding is almost fully maximised in all three crystal structures with the observed hydrogen bonding donor : acceptor ( $D: A)$ ratio for the two moieties is $1: 2$ for benzamide, $2: 1$ for water or a total $D: A=3: 3$ in $\mathbf{M p m} \cdot \mathbf{H}_{2} \mathbf{O}$, (I). Likewise in $\mathbf{N p m F}$ $\cdot \mathrm{H}_{2} \mathrm{O}$, (II) the $\mathrm{D}: \mathrm{A}=3: 3$ with the water as a single hydrogen bond acceptor (from N1) and with two donor $\mathrm{O}-\mathrm{H}$ groups from $\mathrm{O} 1 \mathrm{~W}$ providing a total of three medium strength hydrogen bonds (Table 2). In $\mathbf{C l p m} \cdot \mathbf{2} \mathbf{H}_{\mathbf{2}} \mathbf{O}$ the crystal structure has an observed $\mathrm{D}: \mathrm{A}$ ratio for each of the three moieties Clpm, $\mathrm{H}_{2} \mathrm{O}, \mathrm{H}_{2} \mathrm{O}$ as $(1: 2,2: 2,2: 1)$ or a total $D$ : $A=5: 5$ from a calculated D:A ratio of $6: 5$ if $02 W$ had a maximum $D: A=2: 2$. A total of 5 classical hydrogen bonds are observed (Table 2). The hydrogen bonding interactions (as $\mathrm{O}-\mathrm{H} \cdots \mathrm{O}, \mathrm{N}-\mathrm{H} \cdots \mathrm{O}, \mathrm{O}-\mathrm{H} \cdots \mathrm{N}$ ) are such that the $\mathrm{D} \cdots \mathrm{A}$ geometric distances are typically from $2.80-2.85 \AA$ and with $\mathrm{D}-\mathrm{H} \cdots \mathrm{A}$ angles of $170-175^{\circ}$. Of interest is that two of the three structures contain a meta-aminopyridine moiety which is oriented to easily form a hydrogen bonded assembly containing two benzamides and two water molecules. Of further note is the reluctance of the benzamides 
and pyridine carboxamides to form hydrate or even solvate derivatives despite crystallisation of these series of compounds from a wide range of solvents and conditions. ${ }^{[7-10,22]}$

\section{Hirschfeld Surface Analysis}

Hirshfeld surface analysis of the three benzamide hydrate crystals (I) to (III) was undertaken with the MoProViewer software ${ }^{[23]}$ to further characterize on a statistical basis the intermolecular contacts. The Hirshfeld surface is representative of the region in space where contacts and interactions arise between molecules. Therefore, quantitative insights into the chemical nature of intermolecular interactions can assist in understanding crystal structure packing. Integral Hirshfeld surfaces were generated around the benzamide and water molecules by selecting moieties in the crystal which are not directly in contact with each other. The hydrogen atoms $\mathrm{Hc}$ bound to carbon were distinguished from the more polar $\mathrm{Ho} / \mathrm{n}$ bound to oxygen or nitrogen atoms. For $\mathrm{NmpF}$, the conformer of major occupancy was considered.

The two most prominent chemical types on the Hirshfeld surface are the hydrophobic hydrogen $\mathrm{Hc}$ and carbon atoms whose proportions together sum up to 55$75 \%$ in the three structures (I) to (III) (Table 3a-c). As a result, the hydrophobic contacts $\mathrm{Hc} \cdots \mathrm{C}, \mathrm{C} \cdots \mathrm{C}$ and $\mathrm{Hc} \cdots \mathrm{Hc}$ are the most abundant interactions, except in the dihydrate compound $\mathrm{Clpm}$ where $\mathrm{O} \cdots \mathrm{Ho} / \mathrm{n}$ is the second major contact type (Table 3c).

Table 3a. Chemical proportions on the Hirshfeld surface, \% contact types and their enrichment ratios for $\mathrm{Mpm} \times \mathrm{H}_{2} \mathrm{O}(\mathrm{I})$. The major interaction types and the most enriched are in bold. The hydrogen atoms ( $\mathrm{Ho} / \mathrm{n}$ and, $\mathrm{Hc}$ ) bound to $\mathrm{O} / \mathrm{N}$ and $\mathrm{C}$ are distinguished, as their electrostatic properties are different.

\begin{tabular}{|c|c|c|c|c|c|}
\hline $\begin{array}{c}\text { Atom } \\
\% \\
\end{array}$ & $\begin{array}{c}\mathrm{Ho} / \mathrm{n} \\
11.6 \\
\end{array}$ & $\begin{array}{c}C \\
31.2 \\
\end{array}$ & $\begin{array}{c}\mathrm{N} \\
4.7 \\
\end{array}$ & $\begin{array}{c}0 \\
8.9 \\
\end{array}$ & $\begin{array}{c}\mathrm{Hc} \\
43.6\end{array}$ \\
\hline Atom & $\mathrm{Ho} / \mathrm{n}$ & C & N & $\mathrm{O}$ & $\mathrm{Hc}$ \\
\hline $\mathrm{Hn} / \mathrm{O}$ & 0.01 & & & & \\
\hline C & 3.29 & 14.5 & $\%$ contacts & & $\mathrm{Mpm} \times \mathrm{H}_{2} \mathrm{O}$ \\
\hline $\mathrm{N}$ & 4.18 & 2.78 & 0.00 & & \\
\hline $\mathrm{O}$ & 6.86 & 0.67 & 0.00 & 0.00 & \\
\hline $\mathrm{Hc}$ & 10.05 & 26.42 & 2.35 & 10.76 & 18.11 \\
\hline $\mathrm{Hn} / \mathrm{O}$ & 0.01 & & & & \\
\hline C & 0.43 & 1.50 & & Enrichment & \\
\hline $\mathrm{N}$ & 3.68 & 0.96 & 0.00 & & \\
\hline $\mathrm{O}$ & 3.08 & 0.12 & 0.00 & 0.00 & \\
\hline $\mathrm{Hc}$ & 0.96 & 0.99 & 0.59 & 1.37 & 0.98 \\
\hline
\end{tabular}

The contact enrichment ratio is an indicator of the likelihood of chemical species to form intermolecular interactions with themselves and other species. ${ }^{[24]}$ In all cases, the most enriched contacts are $\mathrm{Hn} / \mathrm{o} \cdots \mathrm{N}$ (with an $E$ ratio between 3.3 and 3.7), followed by $\mathrm{Hn} / \mathrm{O} \cdots \mathrm{O}$ (with an $E$ ratio between 2.8 and 3.1 ) illustrating that these hydrogen bonds are presumably the driving force in the crystal packing. The hydrogen bonds towards the $\mathrm{N}$ atom are

Table 3b. Chemical proportions on the Hirshfeld surface, \% contact types and their enrichment ratios for $\mathrm{NmpF} \cdot \mathrm{H}_{2} \mathrm{O}(\mathrm{II})$.

\begin{tabular}{ccccccc}
\hline Atom & $\mathrm{Ho} / \mathrm{n}$ & $\mathrm{C}$ & $\mathrm{N}$ & $\mathrm{O}$ & $\mathrm{F}$ & $\mathrm{Hc}$ \\
\% surface & 12.6 & 32.2 & 4.6 & 9.5 & 5.8 & 35.2 \\
\hline $\mathrm{Hn} / \mathrm{o}$ & 0.20 & & & & & \\
$\mathrm{C}$ & 7.1 & 11.9 & & \% contacts & $\mathrm{NmpF} \cdot \mathrm{H}_{2} \mathrm{O}$ \\
$\mathrm{N}$ & 4.6 & 3.4 & 0.0 & & & \\
O & 8.1 & 4.4 & 0.3 & 0.0 & & \\
F & 0.0 & 0.9 & 0.7 & 0.0 & 0.0 & \\
Hc & 6.6 & 24.0 & 0.2 & 6.6 & 10.5 & 10.4 \\
\hline Hn/o & 0.11 & & & & & \\
C & 0.83 & 1.17 & & & & \\
N & 3.7 & 1.17 & 0.00 & & Enrichment & \\
O & 3.1 & 0.72 & 0.33 & 0.00 & & \\
F & 0.00 & 0.23 & 1.27 & 0.00 & 0.00 & \\
Hc & 0.72 & 1.10 & 0.05 & 0.99 & 2.5 & 0.88 \\
\hline The presentationand data analysisare similarto Table 3a. &
\end{tabular}

The presentation and data analysis are similar to Table $3 a$.

Table 3c. Chemical proportions on the Hirshfeld surface, \% contact types and their enrichment ratios for Clpm $\cdot 2 \mathrm{H}_{2} \mathrm{O}$ (III).

\begin{tabular}{ccccccc}
\hline Atom & $\mathrm{Ho} / \mathrm{n}$ & $\mathrm{C}$ & $\mathrm{N}$ & $\mathrm{O}$ & $\mathrm{Cl}$ & $\mathrm{Hc}$ \\
$\%$ & 17.41 & 26.44 & 4.35 & 12.13 & 10.85 & 28.81 \\
\hline $\mathrm{Hn} / \mathrm{o}$ & 1.87 & & & & & \\
$\mathrm{C}$ & 6.79 & 13.30 & & \% contacts & & $\mathrm{Clpm} \times 2 \mathrm{H}_{2} \mathrm{O}$ \\
$\mathrm{N}$ & 5.32 & 1.77 & 0.01 & & & \\
$\mathrm{O}$ & 12.97 & 2.46 & 0.00 & 0.00 & & \\
$\mathrm{Cl}$ & 0.00 & 6.54 & 0.00 & 0.17 & 2.54 & \\
$\mathrm{Hc}$ & 9.27 & 7.37 & 1.21 & 8.72 & 10.76 & 8.92 \\
\hline $\mathrm{Hn} / \mathrm{O}$ & 0.52 & & & & & \\
$\mathrm{C}$ & 0.69 & 2.00 & & Enrichment & & \\
$\mathrm{N}$ & 3.3 & 0.83 & 0.07 & & & \\
$\mathrm{O}$ & 2.8 & 0.39 & 0.00 & 0.00 & & \\
$\mathrm{Cl}$ & 0.00 & 1.12 & 0.00 & 0.06 & 2.0 & \\
$\mathrm{Hc}$ & 0.88 & 0.52 & 0.53 & 1.30 & 1.7 & \\
\hline The presentation and data analysis are similar to Table 3a. & \\
\hline
\end{tabular}


systematically more enriched than those towards the 0 atom. The weaker $\mathrm{Hc} \cdots \mathrm{O}$ hydrogen bonds are slightly enriched except for the NpmF compound where $E$ is unitary. The weaker $\mathrm{Hc} \cdots \mathrm{N}$ interactions are absent or under-represented, presumably due to competition with the much stronger $\mathrm{Hn} / \mathrm{O} \cdots \mathrm{N}$ hydrogen bonds (Table $3 \mathrm{~b}$ ).

In a statistical study of several families of halogenated compounds, ${ }^{[25]}$ it was found that the hydrogen $\mathrm{Hc}$ is a preferred partner for halogen atoms. This is the case in the two halogenated benzamides reported herein with $E(\mathrm{~F}, \mathrm{Hc})$ $=2.5$ in (II) and $E(\mathrm{Cl}, \mathrm{Hc})=1.7$ in (III). The Hc chemical type constitutes by far the major partner for the $(\mathrm{F}, \mathrm{Cl})$ halogen atoms. The chlorine $\cdots$ chlorine interaction is also quite overrepresented in the Clpm structure with a $E=2$ value as the halogen atom happens to be in proximity of a symmetry related atom (Table 3c).

The hydrophobic C...C contacts are enriched due to extensive parallel offset $\pi \cdots \pi$ stacking between aromatic rings in the three structures (I) to (III). ${ }^{[26]}$ This type of interaction has been analysed and well-described by Martinez and Iverson in a recent review and with descriptors for the various types of stacking arrangements. ${ }^{[26]}$ The $\mathrm{Clpm} \cdot 2 \mathrm{H}_{2} \mathrm{O}$ structure is particularly rich in C...C contacts $(E=2.0)$ due to parallel offset $\pi \cdots \pi$ stacking between molecules related by a translation along the short axis $a=4.562 \AA$ resulting in the structure to have an under-representation of $\mathrm{Hc} \cdots \mathrm{C}$ hydrophobic interactions. The $\mathbf{N m p F} \cdot \mathbf{H}_{2} \mathrm{O}$ compound is the only structure with a weak $\mathrm{C}-\mathrm{H} \cdots \pi$ interaction, as $\mathrm{C} 25-$ $\mathrm{H} 25 \cdots \pi$ (fluorophenyl). This is rendered possible by the very different orientation of the two aromatic rings at a $68.76(6)^{\circ}$ angle and is corroborated with a slight enrichment of $\mathrm{Hc} \cdot \cdots \mathrm{C}$ contacts. The $\mathrm{C} \cdot \mathrm{H} \mathrm{Hc}$ and $\mathrm{Hc} \cdot \cdots \mathrm{Hc}$ hydrophobic contacts are generally mildly enriched or impoverished. In all three crystal structures of (I) to (III), electrostatically unfavourable self-contacts between charged atoms such as $\mathrm{Hn} / \mathrm{O} \cdots \mathrm{Hn} / \mathrm{o}, \mathrm{O} \cdots \mathrm{O}$ or $\mathrm{N} \cdots \mathrm{N}$ are strongly avoided.

\section{Summary Comparisons}

The two distinct approaches provide information that enhances the study of hydrates (I) to (III). Of note is the importance of the $\mathrm{O}-\mathrm{H} \cdots \mathrm{O} / \mathrm{N}$ and $\mathrm{N}-\mathrm{H} \cdots \mathrm{O}$ interactions that are seen to dominate in hydrogen bonding interactions in the crystal structures and in the enrichment studies. In all three structures the $\mathrm{Hn} / \mathrm{o} \cdots \mathrm{N}$ is more enriched by $18-19 \%$ than the Hn/o...O (Tables $3 a-c)$. Of further note is that in $\mathrm{NmpF} \cdot \mathrm{H}_{2} \mathbf{O}$, there is parallel offset $\pi \cdots \pi$ stacking with a

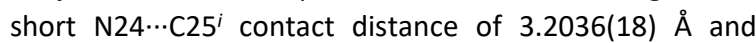
$\mathrm{C} 25 \cdots \mathrm{C} 25^{i}=3.346(2) \AA$ ) involving the pyridine rings, with the $\mathrm{C} \cdots \mathrm{C}$ contacts lower and the $\mathrm{C} \cdots \mathrm{N}$ contacts raised in (II) when compared to both (I) and (III). ${ }^{[26]}$ This difference is also noted in the enrichment statistics as well. The effect of the global C...C contacts in (I) and (III) is more notable and this is something that may not be easily discerned in crystal structure analysis by programs such as SHELXL or PLATON. ${ }^{111,14]}$

\section{CONCLUSIONS AND FUTURE WORK}

In our research on isomer series of benzamides and carboxamides to date we have observed the paucity of hydrates or even solvates. When a hydrate structure is structurally characterised it is noted that the hydrate is easily accommodated in the crystal structure and the hydrogen bonding is usually balanced in $\mathrm{D}: \mathrm{A}$ ratios and maximised in the structure. Of note is that there are two recent examples of neutral benzamide or carboxamide active pharmaceutical ingredients as hydrates: niclosamide ${ }^{[27]}$ and pranlukast. ${ }^{[28]}$ Some experimental drugs are also known as either neutral benzamide/carboxamide hydrates ${ }^{[29]}$ or hydrochloride hydrates. ${ }^{[30]}$ However, there is a growing group of approved and experimental protein kinase blockers including so called targeted anticancer drugs that have become lifesaving therapies: these are mostly longer but simple organic molecules featuring benzamide linkers and moieties. ${ }^{[31-33]}$ It may be expected that their hydrates could become important as APIs with different release rates and pharmacokinetics or be more stable in formulations in future pharmaceutical research. From a structural viewpoint, additional knowledge gained from series of pharmaceutical hydrates such as (I) to (III) will aid in pharmaceutical drug design and development.

Acknowledgment. This research was funded by the Programme for Research in Third Level Institutions (PRTLI) Cycle 4 (Ireland) and co-funded through the European Regional Development Fund (ERDF), part of the European Union Structural Funds Programme (ESF) 2007-2013. JFG thanks the School of Chemical Sciences, Dublin City University for grants in aid of chemical and crystallographic research. PM thanks the $T^{3}$ (PRTLI-IV) program for a studentship. JFG and CJ thank the Université de Lorraine and Region Lorraine for a "Chercheur d'Avenir" grant.

Supplementary Information. Crystallographic data for the three $\mathrm{Mpm} \cdot \mathrm{H}_{2} \mathrm{O}, \mathrm{NpmF} \cdot \mathrm{H}_{2} \mathrm{O}$ and $\mathrm{Clpm} \cdot 2 \mathrm{H}_{2} \mathrm{O}$ crystal structures have been deposited with the Cambridge Crystallographic Data Centre, CCDC no. 1835885 to 1835887. CIF data may be downloaded from the CCDC website https://summary.ccdc.cam.ac.uk/structuresummary-form or obtained free of charge from The Director, CCDC, 12 Union road, Cambridge, CB2 1EZ, U.K. (fax: +44-1223-336033; e-mail:deposit@ccdc.cam.ac.uk). The data are available as CIF files from the corresponding author Dr. John F. Gallagher. 


\section{REFERENCES}

[1] R. K. Khankari, D. W. Grant, Thermochimica Acta $1995,248,61$.

[2] F. Tian, H. Qu, A. Zimmermann, T. Munk, A. C. Jørgensen, J. Rantanen, J. Pharm. Pharmacol. 2010, 62, 1534.

[3] K. T. Savjani, A. K. Gajjar, J. K. Savjani, ISRN Pharmaceutics 2012, 195727, 1.

[4] S. J. Franklin, U. S. Younis, P. B. Myrdal, J. Pharm. Sci. 2016, 105, 1914.

[5] L. Lange, G. Sadowski, Cryst. Growth Des. 2016, 16, 4439.

[6] A. M. Healy, Z. A. Worku, D. Kumar, A. M. Madi, Adv. Drug Del. Rev. 2017, 117, 25.

[7] P. Mocilac, M. Tallon, A. J. Lough, J. F. Gallagher, CrystEngComm 2010, 12, 3080.

[8] P. Mocilac, K. Donnelly, J. F. Gallagher, Acta Crystallogr. 2012, B68, 189.

[9] P. Mocilac, J. F. Gallagher, CrystEng Comm 2011, 13, 5354.

[10] P. Mocilac, A. J. Lough, J. F. Gallagher, CrystEngComm 2011, 13, 1899.

[11] G. M. Sheldrick, Acta Crystallogr. 2015, C71, 3.

[12] Oxford Diffraction, CrysAlis CCD and CrysAlis RED, 2010, Yarnton, Oxfordshire, U.K.

[13] R. C. Clark, J. S. Reid, Comput. Phys. Commun. 1998, 111, 243.

[14] A. L. Spek, Acta Crystallogr. 2015, D65, 148.

[15] C. F. Macrae, P. R. Edgington, P. McCabe, E. Pidcock, G. P. Shields, R. Taylor, M. Towler, J. van De Streek, J. Appl. Cryst. 2006, 39, 453.

[16] C. R. Groom, I. J. Bruno, M. P. Lightfoot, S. C. Ward, Acta Crystallogr. 2016, B72, 171.
[17] K. M. Steed, J. L. Steed, Chem. Rev. 2015, 115, 2895.

[18] D. Chopra, T. N. Guru Row, CrystEngComm 2008, 10, 54.

[19] S. N. Nayak, M. K. Reddy, D. Chopra, T. N. Guru Row, CrystEngComm 2012, 14, 200.

[20] P. Mocilac, J. F. Gallagher, Acta Crystallogr. 2015, E71, 1366.

[21] J. F. Gallagher, S. Alley, M. Brosnan, A. J. Lough, Acta Crystallogr. 2010, B66, 196.

[22] J. F. Gallagher, S. Alley, A. J. Lough, Inorg. Chim. Acta 2016, 444, 113.

[23] B. Guillot, E. Espinosa, L. Huder, C. Jelsch, Acta Crystallogr. 2014, A70, C279.

[24] C. Jelsch, C. Ejsmont, L. Huder, IUCrJ 2014, 1, 119.

[25] C. Jelsch, S. Soudani, C. Ben Nasr, IUCrJ 2015, 2, 327.

[26] C. R. Martinez, B.L. Iverson, Chem. Sci. 2012, 3, 2091.

[27] I. Sovago, A. D. Bond, Acta Crystallogr. 2015, C71, 394.

[28] H. Sugihara, Y. Matsui, H. Takeuchi, I. Wilding, A. Connor, K. Abe, A. Nishiura, Eur. J. Pharm. Sci. 2014, $53,62$.

[29] C. E. Chandler, D. E. Wilder, J. L. Pettini, Y. E. Savoy, S. F. Petras, G. Chang, J. Vincent, H. J. Harwood, J. Lipid Res. 2003, 44, 1887.

[30] H. Sagawa, H. Terasaki, M. Nakamura, M. Ichikawa, T. Yata, Y. Tokita, M. Watanabe, Exp. Neurol. 2007, 205, 230.

[31] S. F. Zhou, S. P. Tan, D. Q. Fang, R. Zhang, W. C. Lin, W. J. Wu, K. C. Zheng, RSC Adv. 2016, 6, 85355.

[32] N. Miyamoto, Y. Oguro, T. Takagi, H. Iwata, H. Miki, A. Hori, S. Imamura, Bioorg. Med. Chem. 2012, 20, 7051.

[33] G. C. Gajo, D. R. Silva, S. J. Barigye, E. F. F. da Cunha, Mol. Inf. 2018, 37, 1700080. 